\title{
Determinants of facility readiness for integration of family planning with HIV testing and counseling services: evidence from the Tanzania service provision assessment survey, 2014-2015
}

\author{
Deogratius Bintabara ${ }^{1,2}$, Keiko Nakamura $^{1 *}$ (1) and Kaoruko Seino ${ }^{1}$
}

\begin{abstract}
Background: Global policy reports, national frameworks, and programmatic tools and guidance emphasize the integration of family planning and HIV testing and counseling services to ensure universal access to reproductive health care and HIV prevention. However, the status of integration between these two services in Tanzanian health facilities is unclear. This study examined determinants of facility readiness for integration of family planning with HIV testing and counseling services in Tanzania.

Methods: Data from the 2014-2015 Tanzania Service Provision Assessment Survey were analyzed. Facilities were considered ready for integration of family planning with HIV testing and counseling services if they scored $\geq 50 \%$ on both family planning and HIV testing and counseling service readiness indices as identified by the World Health Organization. All analyses were adjusted for clustering effects, and estimates were weighted to correct for non-responses and disproportionate sampling. Descriptive, bivariate, and multivariate logistic regression analyses were performed.

Results: A total of 1188 health facilities were included in the study. Of all of the health facilities, 915 (77\%) reported offering both family planning and HIV testing and counseling services, while only 536 (45\%) were considered ready to integrate these two services. Significant determinants of facility readiness for integrating these two services were being government owned $[\mathrm{AOR}=3.2 ; 95 \% \mathrm{Cl}, 1.9-5.6]$, having routine management meetings $[\mathrm{AOR}=1.9 ; 95 \% \mathrm{Cl}, 1.1-3.3]$, availability of guidelines [AOR $=3.8 ; 95 \% \mathrm{Cl}, 2.4-5.8]$, in-service training of staff $[\mathrm{AOR}=2.6 ; 95 \% \mathrm{Cl}, 1.3-5.2]$, and availability of laboratories for HIV testing [AOR $=17.1 ; 95 \% \mathrm{Cl}, 8.2-35.6]$.

Conclusion: The proportion of facility readiness for the integration of family planning with HIV testing and counseling in Tanzania is unsatisfactory. The Ministry of Health should distribute and ensure constant availability of guidelines, availability of rapid diagnostic tests for HIV testing, and the provision of refresher training to health providers, as these were among the determinants of facility readiness.
\end{abstract}

Keywords: Facility readiness, Integration, Family planning, HIV testing and counseling, Tanzania

\footnotetext{
* Correspondence: nakamura.ith@tmd.ac.jp

${ }^{1}$ Department of Global Health Entrepreneurship, Division of Public Health,

Graduate School of Tokyo Medical and Dental University, 1-5-45 Yushima,

Bunkyo-ku, Tokyo 113-8519, Japan

Full list of author information is available at the end of the article
} 


\section{Background}

The HIV pandemic remains a major public health problem worldwide, and its effects are especially devastating in Sub-Saharan Africa (SSA) [1]. Approximately, 25.5 million (69\%) of the estimated 36.7 million people living with HIV globally in 2016 were from SSA, with 19.4 million living in East and Southern Africa, a region that accounted for about $44 \%$ of new HIV infections globally [2]. Moreover, adolescents and young adults, especially women aged 15-24 years old, were reported to be at high risk of acquiring new HIV infection $[2,3]$. This burden of the HIV pandemic in SSA is in parallel with the challenges of the unmet needs for family planning (FP), which results in a high fertility rate [4]. Previous reports have shown that about 53 million women in this region want to prevent pregnancy but lack access to contraception $[5,6]$. A high unmet need for FP in SSA has also been reported among HIV-positive women [7, 8], which has compromised efforts to prevent about 160,000 HIVpositive newborns annually due to unintended pregnancies [9-12].

Countries with the greatest HIV burdens also have high unmet needs for FP, and the same people that are at risk of unintended pregnancy are also at risk of HIV infection [13]. The incidence of unintended pregnancies remains alarmingly high among HIV-positive women in SSA [14], but the integration of FP into HIV programs has been underutilized $[15,16]$. Demographic and Health Survey (DHS) data analysis indicated that about $14 \%$ of HIV-positive women in six African countries have unmet needs for FP, although they are in normal contact with the health system for HIV care [17].

In 2009, about 1.4 million people were estimated to be living with HIV in Tanzania; approximately 200,000 of these being children under 15 years of age, and $90 \%$ of them had acquired the infection through mother-tochild transmission (MTCT) [18], which is the second most common method of HIV transmission [19]. The use of FP is one of the comprehensive strategies available for the prevention of MTCT as well as unintended pregnancies among HIV-positive women or couples, however, this strategy is not useful in case HIV positive women or couples desire to have children [20]. Despite the advantages of FP for HIV-positive and non-HIVpositive women and couples, in Tanzania, about $68 \%$ of women of reproductive age are currently not using any modern method of contraception and $22 \%$ have unmet needs for FP [21]. This places Tanzania among the countries with a high fertility rate (5.2 births per woman) [21], which is slightly above the African average of 4.7 births per women reported in 2015 [22].

Prior to 2008, FP and HIV services were implemented under different and independent operational structures in Tanzania $[13,23]$. These structures arose even though the unmet need for FP and the HIV epidemic share similar backgrounds, such as poverty, poor access to health services, and gender inequality [13]. Clients looking for FP services and those seeking HIV testing and counseling services (HTC) share several needs and concerns [24]. Therefore, providing these two services separately results in several unnecessary trips as well as adding to the financial burden, high level of stigma, and lack of follow-up visits [25]. On the other hand, integrating these services enables health facilities to offer FP services to those at risk of HIV and those living with HIV $[11,25,26]$. This reduces the spread of HIV infection by maximizing the use of contraception among these groups [12, 27]. Several studies have provided evidence confirming the feasibility and effectiveness of integrating these services [28-33]. In addition, several global policy reports, national frameworks, and programmatic tools and guidance suggest that providers should integrate FP into HTC services to achieve universal access to reproductive health care and HIV prevention [34-36].

Facility Readiness for the Integration of FP with HTC services (FRIFHS) reflects the willingness or ability of a facility, regardless of its level, to offer FP and HTC services at a single time point to ensure and maximize collective health outcomes $[13,37,38]$. Health facilities in Tanzania are categorized into three groups depending on the population coverage, expertise, and availability of services: dispensaries/clinics, which are the lowest level of health facilities that provide preventative and curative outpatient services, including normal delivery and are expected to serve up to a total of 10,000 inhabitants in local communities; health centers, which offer all services available in the dispensaries but have further capacity to provide inpatient services and are also expected to perform some surgical interventions, e.g., emergency obstetric care; and hospitals, which provide similar services to health centers but at a greater level of expertise given the higher levels of clinical and nursing care capability and laboratory/radiology diagnostic capacity. Despite the differences in functions, all three levels are expected to provide primary health care, such as HTC and FP services [39].

In 2008, the government of Tanzania established a policy supporting the integration of FP with HTC services. Therefore, the national policies for HIV/AIDS care and treatment were revised to include FP as a core component [23]. The FP components were included in at least one of the six major HIV policies and guidelines, while "HIV/AIDS" components were included in at least one of the four major FP and Reproductive Health (RH) policies and guideline documents [40]. Despite this effort to establish integration policy and the highlighted benefits of integrating FP with HTC services [41-43], only $38 \%$ of HIV-infected women 
attending care and treatment clinics (CTC) in Tanzania reported having discussed FP with care providers. Around $70 \%$ of those who missed the discussion did not intend to become pregnant within the following 6 months [23]. This may be due to poor implementation of integration strategies due to unknown factors. However, some studies have attempted to assess client factors associated with the use of integrated services [44-47]. Possible issues that may compromise integrated services have been proposed, such as procurement problems, the lack of continuous supply of equipment, and expenses associated with laboratory tests [48-50]. Furthermore, inadequate training, lack of supervision, heavy workload, lack of incentive, and staff burnout have been reported as provider-related barriers to the provision of integrated services [50-55].

Despite these factors, the majority of studies have concentrated on the availability of services [48-50, 56, 57] and have not examined whether the facilities are actually ready to offer the desired integrated services. In fact, the availability of services does not guarantee that clients will receive integrated services if the facilities or providers are not willing to offer these services $[58,59]$. For example, integration of FP with HIV services was introduced in Tanzania in 2008, but the majority of clients are still unable to receive integrated care [9]. Therefore, facility readiness is an important area of study, as little is actually known regarding this issue. The present study was performed to assess the current extent and determinants of FRIFHS in Tanzania using a nationwide representative sample.

\section{Methods}

\section{Data source}

This study used data from the Tanzania Service Provision Assessment (Tanzania SPA) Survey, conducted between 20 October 2014 and 21 February 2015. The survey was undertaken by Tanzania's National Bureau of Statistics (NBS) and the Office of the Chief Government Statistician (OCGS) in collaboration with the Ministry of Health and Social Welfare (MoHSW) - Mainland, and the Ministry of Health $(\mathrm{MoH})-$ Zanzibar. This survey is the second facilitybased survey conducted in Tanzania, following the one conducted in 2006. The survey, funded by the United States Agency for International Development (USAID) [60], was designed to provide information on the availability of basic and essential health care services and on service readiness. It assessed the presence and functioning of components essential for quality service delivery for child health, maternal and newborn care, FP, antenatal care, sexually transmitted infections, HIV/AIDS, and non-communicable diseases [60].

\section{Sample size and sampling procedure}

The methodology of this survey is reported elsewhere, but briefly, from a list of 7102 verified (active) health facilities as a sampling frame; 1200 facilities were randomly selected for inclusion in the survey. The sample was designed to provide nationally representative results according to facility type and managing authority, and regionally representative results for all 25 Tanzania mainland regions and five Zanzibar regions [60]. However, of the 1200 health facilities sampled, seven refused to participate in the survey, four had closed down, and one facility could not be reached. Finally, a total of 1188 facilities took part in this survey.

\section{Data collection}

The 2014-2015 Tanzania SPA survey data were collected between 20 October 2014 and 21 February 2015, and some facilities that were not covered previously were revisited from 2 to 13 March 2015. The survey used four main types of data collection tools: Facility Inventory questionnaire; Health Provider Interview questionnaire; Observation Protocols for antenatal care (ANC), FP, and services for sick children; and Exit Interview questionnaires for ANC and FP clients and for caregivers of sick children whose consultations were observed [60].

\section{Data processing and management}

An online DHS website request for permission to access the Tanzania SPA survey dataset was performed by the first author on 29 October 2016. Two days later, the authors received full online access to all four (Facility, Health Provider, Observation, and Client Exit) files of Tanzania SPA survey dataset. Most of the data analyzed in this study were obtained from the Facility Inventory file, but one variable regarding staff that had received refresher training was obtained from the Health Provider file. The data in these file were edited, cleaned, and recoding was performed for variables of interest to obtain meaningful information for addressing our research questions. Data cleaning was performed by calculating the frequencies and sorting. Finally, these two files were merged in Stata together into new file (dataset) using facility identification as a unique identifier of these two files. As the Facility Inventory was used as the master file and Provider was used as the using file, the merge command in Stata was performed at 1:1; therefore, the unit of analysis of the new file remained at the facility level. After merging, 12 cases from the Facility Inventory file were not matched. This was because 12 facilities sampled were not interviewed. Therefore, they were regarded as missing variables and were excluded from further analysis. As the facilities sampled were not evenly distributed and the response rate may be very different between regions or facility type, over- and under- 
sampling were performed in the regions with fewer and more facilities, respectively, prior to data collection. Before analysis, therefore, facility weight was applied to restore the actual representativeness and corrected for sampled data.

\section{Operational definitions}

Facility readiness: defined in this study as the willingness or state of the health facility to provide FP and HTC as integrated services.

Refresher training: defined as on-the-job training provided to health providers without taking into consideration their roles to update their knowledge, skills, and technical competence to improve health care related to the services offered to clients.

\section{Measurement of variables \\ Dependent variable}

The FRIFHS was measured based on the scores of FP and HTC service readiness indices. The scores were determined using the WHO approach, and FP and HTC readiness indicators were identified according to the WHO Service Availability and Readiness Assessment (SARA) Manual [38]. Using this approach, the FP service readiness index was categorized into three domains; staff and guidelines, equipment and medicines/commodities. The first domain consisted of staff and guidelines, which had two indicators, i.e., guidelines on FP and staff trained in FP. The facilities with guidelines and at least one staff member that had received refresher training in FP within 24 months were categorized as "Yes," while those without such guidelines or at least one staff member receiving refresher training in FP within 24 months were categorized as "No." The second domain was equipment, which had one indicator, i.e., the presence of blood pressure (BP) apparatus. Facilities with BP apparatus were categorized as "Yes," while those without were categorized as "No." The third domain was medicine and commodities, which had four indicators, i.e., the availabilities of progestin-only pills, combined oral pills, injectable contraceptives (combined or progestin-only), and condoms. Facilities with the availability of these means of contraception were categorized as "Yes," while those without were categorized as "No." The HTC service readiness index was categorized into three domains. The first domain was staff and guidelines, which had two indicators, i.e., guidelines and staff trained in HTC. Facilities with guidelines and at least one staff member that had received refresher training in HTC within 24 months were categorized as "Yes," while those without such guidelines and no staff members receiving HTC refresher training within 24 months were categorized as "No." The second domain was laboratory capacity. Facilities with the capability to perform rapid diagnostic tests or ELISA for HIV were categorized as "Yes," while those without were categorized as "No." The third domain was supplies/commodities, which had one indicator; facilities with the availability of condoms at testing and counseling sites were categorized as "Yes," while those without were categorized as "No."

Each index (FP and HTC service readiness) was then totaled by adding the presence of each indicator, with equal weight given to each of the domains and each of the indicators within the domains. As the target was $100 \%$, each domain accounted for $33.3 \%(100 \% / 3)$ of the index. The percentage for each indicator within the domain was equal to $33.3 \%$ divided by the number of indicators in that domain. The FP and HTC service readiness indices for each facility were then calculated by summing the percentages. Facilities with scores of at least $50 \%$ for the FP service readiness index and 50\% for the HTC service readiness index were considered to be ready for the integration of FP with HTC services (i.e., FRIFHS), while those that scored less than $50 \%$ for each index were not considered to be ready (i.e., not FRIFHS) $[38,61]$. An additional table in word document file summarizes this measurement procedure in more details [see Additional file 1].

\section{Independent variables}

Facility type was coded as "1" for a hospital, "2" for a health center, and " 3 " for a clinic or dispensary. The residence was coded as "0" for urban and " 1 " for rural. Managing authority was coded as " 0 " for a private facility and " 1 " for the public facility. Routine management meetings were coded as "Yes" for facilities reporting that they performed routine management meetings at least on a quarterly basis and "No" for those that reported having no such meetings at least on the quarterly basis. External supervision was coded as "Yes" for facilities reporting having receiving external supervision in the past 3 months and "No" for those without such supervision. Location was categorized as "0" for Zanzibar and "1" for the mainland. FP and HTC guidelines were categorized as " 0 " for facilities without guidelines for both FP and HTC and "1" for facilities with guidelines for both FP and HTC. Staff trained in FP and HTC were categorized as " 0 " for facilities without staff trained in both FP and HTC and "1" for facilities with staff trained in both FP and HTC. Laboratory capacity was categorized as "0" or " 1 " for facilities without and with laboratory capacity to test for HIV, respectively.

\section{Statistical analysis}

Data were analyzed using Stata 14 (StataCorp, College Station, TX). For all analyses, the "svy" set command in Stata was used to adjust for the complex sampling design used by Tanzania SPA survey. All estimates were 
weighted to correct for non- responses and disproportionate sampling.

In descriptive analyses, categorical variables were summarized using proportions and then presented in tables and graphs. An unadjusted logistic regression model was fitted to examine whether there were any associations between the dependent variable (FRIFHS) and the independent (health facility) variables (location, residence, facility type, managing authorities, management meetings, FP and HTC guidelines, staff trained in FP and HTC, laboratory capacity for HIV testing, and external supervision) using multilevel modeling. All variables with $P<0.2$ were fitted into the multiple logistic regression models using the stepwise (backward elimination) method to test for the association of each variable with the dependent variable using a 5\% significance level. The resulting final model included all of the variables that determined the FRIFHS. The $P$-value and $95 \%$ confidence interval (CI) for the odds ratio (OR) were used to confirm the significance of the associations. In all analyses, $P<0.05$ was taken to indicate statistical significance.

\section{Ethical considerations}

The 2014-2015 Tanzania SPA survey was approved by Tanzania's National Institute for Medical Research (NIMR), the Zanzibar Medical Ethics and Research Committee (ZAMREC), and the Institutional Review Board of ICF International in the USA. Before interviews were performed, informed consent was obtained from the manager, the person-in-charge of the facility, or the most senior health worker responsible for client services present at the facility. The respondents were adequately informed regarding all relevant aspects of the study, including its aim and interview procedures. Respondents that accepted for their facilities to participate in the study signed informed consent.

\section{Results}

Background characteristics of selected health facilities

Table 1 presents a summary of the background characteristics of included health facilities. A total of 1188 health facilities representing a 99\% response rate were included in the analysis. The majority $(1044,95.3 \%)$ were from the Tanzania mainland, and $864(72.7 \%)$ were located in rural settings. Most of the facilities (1013, $85.3 \%)$ were dispensaries or clinics, and 857 (72.2\%) were public facilities. The majority $(922,77.6 \%)$ reported having routine management meetings. Among all of the facilities, 523 (44.1\%) reported having both FP and HTC guidelines in place, but only 136 (11.5\%) reported having at least one health provider that had received training in both FP and HTC services. The majority $(842,70.9 \%)$ reported having a laboratory for HIV testing, but only a
Table 1 Percentage distribution of surveyed facilities according to background characteristics, Tanzania SPA 2014-15 $(n=1188)$

\begin{tabular}{|c|c|c|}
\hline Variable & Number (weighted) $(n)$ & Percentage (\%) \\
\hline \multicolumn{3}{|l|}{ Facility location } \\
\hline Zanzibar & 44 & 3.7 \\
\hline Mainland & 1144 & 96.3 \\
\hline \multicolumn{3}{|l|}{ Managing authority } \\
\hline Public & 857 & 72.2 \\
\hline Private & 331 & 27.8 \\
\hline \multicolumn{3}{|l|}{ Facility type } \\
\hline Hospital & 46 & 3.9 \\
\hline Health center & 129 & 10.8 \\
\hline Clinic \& dispensary & 1013 & 85.3 \\
\hline \multicolumn{3}{|l|}{ Facility residence } \\
\hline Urban & 324 & 27.3 \\
\hline Rural & 864 & 72.7 \\
\hline \multicolumn{3}{|c|}{ Routine management meetings } \\
\hline No & 266 & 22.4 \\
\hline Yes & 922 & 77.6 \\
\hline \multicolumn{3}{|l|}{ FP and HTC guidelines } \\
\hline Not available & 664 & 55.9 \\
\hline Available & 524 & 44.1 \\
\hline \multicolumn{3}{|c|}{ Staff trained for FP and HTC } \\
\hline Not available & 1052 & 88.5 \\
\hline Available & 136 & 11.5 \\
\hline \multicolumn{3}{|c|}{ Laboratories for HIV testing } \\
\hline Not available & 346 & 29.1 \\
\hline Available & 842 & 70.9 \\
\hline \multicolumn{3}{|l|}{ External supervision } \\
\hline Not done & 34 & 3.0 \\
\hline Done & 1154 & 97.0 \\
\hline
\end{tabular}

few facilities (34, 3.0\%) reported receiving external supervision from a higher ranking facility (Table 1).

\section{Availability of services and health facility readiness for offering FP and HTC services}

Table 2 shows the distributions of availability and readiness of facility for offering FP and HTC services. The majority of the health facilities included in the study reported the availability of HTC $(1039,87.5 \%)$ and availability of FP services $(948,79.8 \%)$, while $(915,77.0 \%)$ reported offering both services. Less than half of the interviewed health facilities $(487,41.0 \%)$ reported having both FP guidelines and at least one health provider that had received refresher training in FP services, while 677 (57.0\%) reported having BP apparatus as important equipment to provide FP services, but only 307 (25.9\%) health facilities reported having progestin-only pills, 
Table 2 Percentage distribution of health facilities with the availability and readiness to offer FP and HTC services, Tanzania SPA 2014-15 $(n=1188)$

\begin{tabular}{lcc}
\hline Variable & *Number (weighted) $(n)$ & *Percentage (\%) \\
\hline Service availability & & 79.8 \\
FP & 948 & 87.5 \\
HTC & 1039 & 77.0 \\
Both & 915 & \\
Components of FP readiness index & 41.0 \\
Staff and guidelines & 487 & 57.0 \\
Equipment & 677 & 25.9 \\
Medicine/commodities & 307 & \\
Components of HTC readiness index & 32.0 \\
Staff and guidelines & 380 & 70.9 \\
Laboratory capacity to test & 842 & \\
HIV & & 56.7 \\
Supplies/commodities & 674 & \\
Overall facility readiness & & 60.6 \\
FP & 720 & 59.0 \\
HTC & 701 & 45.1 \\
Integrated services & 536 & \\
\hline
\end{tabular}

combined oral pills, injectable contraceptives (combined or progestin-only), and condoms. Furthermore, about one third $(380,32.0 \%)$ of the health facilities reported having both HTC guidelines and at least one health provider that had received refresher training in HTC services. However, the majority $(842,70.9 \%)$ reported having a laboratory capacity for HIV testing and 674 (56.7\%) reported the availability of condoms at the testing and counseling site.

Based on the WHO readiness indicator score, only 720 $(60.6 \%)$ and $701(59.0 \%)$ facilities were ready to offer FP and HTC services, respectively, while only 536 (45.0\%) were ready to offer integrated services.

\section{Determinants of facility readiness for integration of FP with HTC services}

Table 3 presents the results of bivariate and multivariate analyses. In bivariate analysis, facility location, type of managing authority, facility residence, routine management meetings, availability of both FP and HTC guidelines, availability of staff trained in both FP and HTC, and availability of a laboratory with capacity for HIV testing were found to be significantly associated with FRIFHS.

In multiple logistic regression analysis, the baseline model included the following variables: FRIFHS as a dependent variable and facility location, managing authority, facility residence, routine management meetings, external supervision, FP and HTC guidelines, staff trained in FP and HTC, and laboratory capacity for HIV
Table 3 Determinants of FRIFHS in bivariate and multivariate analyses, Tanzania SPA 2014-2015 $(n=1188)$

\begin{tabular}{|c|c|c|c|c|}
\hline Variable & COR $[95 \% \mathrm{Cl}]$ & $P$-value & AOR $[95 \% \mathrm{Cl}]$ & $P$-value \\
\hline \multicolumn{5}{|l|}{ Facility location } \\
\hline Zanzibar & 1 & & 1 & \\
\hline Mainland & $1.6[1.1-2.5]$ & 0.043 & $1.3[0.6-2.7]$ & 0.871 \\
\hline \multicolumn{5}{|l|}{ Managing authority } \\
\hline Private & 1 & & 1 & \\
\hline Public & $8.5[5.2-13.8]$ & 0.000 & $3.2[1.9-5.6]$ & 0.000 \\
\hline \multicolumn{5}{|l|}{ Facility type } \\
\hline Hospital & 1 & & & \\
\hline Health center & $1.1[0.8-1.7]$ & 0.478 & - & \\
\hline Clinic \& dispensary & $1.2[0.8-1.7]$ & 0.423 & & \\
\hline \multicolumn{5}{|l|}{ Facility Residence } \\
\hline Urban & 1 & & 1 & \\
\hline Rural & $2.6[1.7-3.9]$ & 0.000 & $1.1[0.6-1.9]$ & 0.759 \\
\hline \multicolumn{5}{|c|}{ Routine management meetings } \\
\hline No & 1 & & 1 & \\
\hline Yes & $1.7[1.1-2.6]$ & 0.010 & $1.9[1.1-3.3]$ & 0.014 \\
\hline \multicolumn{5}{|l|}{ External supervision } \\
\hline Not done & 1 & & 1 & \\
\hline Done & $3.7[0.8-16.9]$ & 0.093 & $1.6[0.2-11.2]$ & 0.65 \\
\hline
\end{tabular}

FP and HTC guidelines

Not available

Available

$7.1[4.8-10.2]$

$0.000 \quad 3.8[2.4-5.8]$

0.000

Staff trained in FP and HTC

Not available
Available

1

Available

$4.7[2.5-8.7]$

$0.000 \quad 2.6[1.3-5.2]$

0.006

Laboratories for HIV testing

Not available $\quad 1 \quad 1$

$\begin{array}{lllll}\text { Available } \quad 32.8[16.5-65.1] & 0.000 & 17.1[8.2-35.6] & 0.000\end{array}$

" 1 " indicates the categories considered as references when comparing odds ratios

- Variable was not included in multivariate analysis because $P>0.2$ in bivariate analysis

testing as independent variables. In the final model, the likelihood of FRIFHS was three times higher among public health facilities (owned by the government) than privately owned facilities $[\mathrm{AOR}=3.2 ; 95 \% \mathrm{CI}, 1.9-5.6]$. Similarly, the likelihood of FRIFHS among facilities that reported having routine management meetings was double that in facilities without such meetings $[\mathrm{AOR}=1.9$; 95\%CI, 1.1-3.3]. In addition, the likelihood of FRIFHS was fourfold higher among facilities that reported having both guidelines for FP and HTC services than in those without both or either of these guidelines $[\mathrm{AOR}=3.8$; 95\%CI, 2.4-5.8]. Furthermore, the likelihood of FRIFHS was 2.5 times higher among facilities that reported having at least one staff member that 
had received training for both FP and HTC services than in those without such staff training $[\mathrm{AOR}=2.6$; 95\% CI, 1.3-5.2]. Finally, the likelihood of FRIFHS was 17 times higher for facilities with, than without a laboratory capable of performing HIV testing $[\mathrm{AOR}=17.1$; 95\% CI, 8.2-35.6].

\section{Discussion}

This study aimed to assess the extent and determinants of FRIFHS in Tanzania. To our knowledge, this is the first study to assess the readiness for integration of FP with HTC services in this region using recommended WHO service readiness indicators, and data obtained from a nationally representative sample with "health facility" as the sampling unit. The results presented here indicated an unsatisfactory proportion of FRIFHS in Tanzania. However, the majority of these facilities showed the increased capability of offering these services independently compared to 10 years ago [40, 62]. In addition, the present study indicated that managing authorities, routine management meetings, the availability of FP and HTC guidelines, refresher staff training in FP and HTC, and the availability of laboratories with capacity for HIV testing were significant determinants of FRIFHS.

The low proportion of FRIFHS observed in this study was in contrast to the findings of a study performed in Uganda to assess the integration of routine rapid HIV screening in urban FP clinics, which indicate that about $78 \%$ of staff were ready for integration and rated it as a successful effort to expand routine HIV testing in FP clinics [63]. This difference in findings may have been because our study involved both urban and rural facilities and also included all types of health facilities, whereas the study performed in Uganda included only urban facilities. In addition, the low proportion of FRIFHS observed in the present study may have been because the integration of FP with HTC was treated as a composite variable obtained by considering several indicators unlike the method used in the previous study in which the readiness for integration was based on the willingness of the staff to integrate these two services.

In most countries, including Tanzania, FP and HTC services are provided through public and private health facilities even though private facilities are operated for profit $[64,65]$. The results of the present study indicated that public health facilities were three times more likely to have integrated FP with HTC services than those in the private sector. Thus, public facilities are more likely to offer integrated services. This conclusion agreed with previous studies indicating the better provision of health services at public than at private facilities [66-69]. This finding may be because most public facilities do not have the mandate to choose the type of service to offer rather than to comply with government policies compared to private facilities where the choice of services offered is dependent on the capacity of investment and demand for services. In addition, as public facilities offer FP and HTC for free, while private facilities tend to charge for these services, this may reduce demand in the private sector and make it seem to not be a worthwhile investment. Public facilities receive allocated funds from the government budget, which in turn receives funds from development partners, resources from nongovernmental organizations, out-of-pocket payments, and funds from health insurance, while private facilities depend on out-of-pocket payments only and some rely on health insurance [70, 71]. However, this finding was in contrast to those of previous studies performed in Pakistan [72], Jordan [73], Thailand [74], and Switzerland [75], and may have been due to the growth of health privatization policies in the latter countries. Privatization of the health sector is still new in Tanzania compared with the other countries mentioned above. Therefore, the majority of private health facilities still choose which types of services to offer for the purpose of profit.

Having regular meetings between the managers and staff members of a facility increases the effectiveness of providing appropriate services to clients. These meetings are sometimes used to monitor if the health workers are doing their job. The results of the present study indicated that the likelihood of FRIFHS among facilities that conducted routine management meetings was double that in those that did not. This difference may reflect that such meetings represent not only a form of monitoring that staff are performing their duties according to the appropriate standards but could also be a method to provide managers and staff members with the opportunity of discussing challenges hindering the provision of integrated services and allow them to propose and work on suitable solutions. These observations were in agreement with those of a previous study conducted in Kenya [59].

The availability of guidelines and staff training are essential to provide guidance, up-to-date knowledge and skills required to deliver integrated services. This study indicated that the proportion of health facilities with both guidelines (FP and HTC) and at least one health provider that had received training (for FP and HTC) was low in Tanzania. The study also indicated that facilities with both FP and HTC guidelines were four times more likely to have FRIFHS status than their counterparts. Thus, the presence of guidelines can improve health care decisions by providing clear guidance regarding what should be integrated [50, 76], but also encourages providers to adhere to standards of care [77]. Therefore, facilities with guidelines are more likely to integrate services. Similar findings have been reported in studies conducted in low- and middle-income countries [78]. 
In Tanzania, it is unusual to have high cadre health professionals at lower-level health facility hence an opportunity for other cadres to gain new skills and knowledge. Therefore, on-the-job refresher training provides all cadres of healthcare providers with the opportunity to acquire extra knowledge, skills, and technical competence regarding health services provided in their workplace. Furthermore, the provision of several services at a single point of contact requires healthcare providers to be sufficiently trained in all aspects of the services concerned to allow them to offer the desired services in an integrated form $[51,78]$. The results of the present study indicated that the proportion of health facilities with at least one staff member trained in providing both FP and HTC was low in Tanzania. These facilities with at least one staff member with FP and HTC training were 2.5 -fold more likely to have FRIFHS compared with their counterparts. This difference may have been because staff members that have received training for the services offered are more likely to practice what they have recently learned. Therefore, they are more likely to request the necessary equipment and medications as well as guidelines for their working station, thereby improving the overall integration of health services within their facilities.

The availability of equipment, medical supplies, and drugs were found to be major factors in the adoption of integrated HIV services [79-81]. The majority of health facilities in this study were found to have laboratories with the capacity for HIV testing (rapid diagnostic kits and ELISA), and these facilities were found to be more likely to have FRIFHS than their counterparts. This can be explained by the fact that the availability of rapid diagnostic kits and ELISA for HIV testing within a facility's laboratory could be because of high HIV prevalence and increased awareness that creating high demand for the services hence these units tend to have them as the part of routine care provision. Our findings were comparable to those of a study performed in Lesotho [82].

The present study is the first to use the Tanzania SPA 2014-2015 dataset, which is a nationwide, representative sample of health facilities, with a response rate of $99 \%$, suggesting that the present findings accurately reflect the present conditions in Tanzania. To improve our analysis of the determinants of FRIFHS, we also adjusted for clustering effects and weighted the analysis to correct for non-responses and disproportionate sampling. However, the present study also had some limitations due to its cross-sectional nature preventing causality assumptions, and therefore the results should be interpreted with caution. In addition, the lack of previous surveys to assess the status and determinants of facility readiness for integration of FP and HTC services using WHO service readiness indicators make it difficult to compare the present findings with those of other studies.

\section{Conclusions}

Analysis of the Tanzania SPA 2014-2015 dataset in this study indicated that the proportion of FRIFHS is unsatisfactory, even though the majority of facilities were ready to offer these services separately. Significant determinants for FRIFHS were being a public facility, having routine management meetings, the presence of HTC and FP guidelines, regular refresher staff training about HTC and FP, and laboratories with the capacity to perform HIV testing.

For Tanzanian health facilities to integrate FP with HTC services, the government, acting through MoHCDGEC, should distribute and ensure constant availability of FP and HTC guidelines and rapid diagnostic tests for HIV, in addition to providing FP and HTC in-service training to health providers. In addition, the MoHCDGEC should make regular visits and provide incentives to private health facilities to encourage the provision and integration of FP with HTC services.

\section{Additional file}

Additional file 1: Summary of measurement procedure of the outcome variable FRIFHS. Table summarizing measurement procedure of the outcome variable FRIFHS. (DOCX $18 \mathrm{~kb}$ )

\section{Abbreviations \\ AIDS: Acquired immunodeficiency syndrome; AOR: Adjusted odds ratio; COR: Crude odds ratio; ELISA: Enzyme-linked immunosorbent assay; FP: Family planning; FRIFHS: Facility Readiness for the Integration of FP with HTC Services; HIV: Human immunodeficiency virus; HTC: HIV testing and counseling; MoHCDGEC: Ministry of Health, Community Development, Gender, Elderly, and Children; MTCT: Mother-to-Child Transmission; SPA: Service provision assessment; SSA: Sub-Saharan Africa; WHO: World Health Organization}

\section{Acknowledgments}

The authors are grateful to ICF International (Rockville, MD), through the DHS program, for providing permission to access the Tanzania SPA $2014-2015$ dataset.

\section{Funding}

There was no funding associated with this study.

\section{Availability of data and materials}

The dataset used for this secondary analysis was generated from the original Tanzanian SPA datasets available in the DHS Program repository: http://dhsprogram.com/data/available-datasets.cfm. The generated dataset is currently stored and accessible by the first author. However, it is available upon request to the first author at the contact address provided in this article.

\section{Authors' contributions}

DB originated the design of the study, performed statistical analysis, interpretation, and drafted the manuscript. KS contributed to interpretation of data, KN contributed to the design of the study and the interpretation data. DB, KS, and KN critically revised the draft manuscript. All authors have read and approved the final manuscript.

\section{Ethics approval and consent to participate}

This study was based on analysis of existing public domain survey data sets that are freely available online with all identifier information detached. The original survey was approved by the Ethics Committee of the ICF Macro at Calverton in the USA and by the National Institute of Medical Research 
Ethics Committee in Tanzania. Therefore, the ethical approval for the current analysis was automatically deemed unnecessary; however, permission to access the Tanzania SPA dataset was requested and granted by ICF Institutional Review Board through DHS program.

\section{Consent for publication}

Not applicable.

\section{Competing interests}

The authors declare that they have no competing interests.

\section{Publisher's Note}

Springer Nature remains neutral with regard to jurisdictional claims in published maps and institutional affiliations.

\section{Author details}

${ }^{1}$ Department of Global Health Entrepreneurship, Division of Public Health, Graduate School of Tokyo Medical and Dental University, 1-5-45 Yushima, Bunkyo-ku, Tokyo 113-8519, Japan. ²Department of Public Health, College of Health Sciences, The University of Dodoma, P.O Box 259, Dodoma, Tanzania.

Received: 23 March 2017 Accepted: 15 December 2017

Published online: 22 December 2017

\section{References}

1. Vitoria M, Granich R, Gilks CF, Gunneberg C, Hosseini M, Were W, et al. The global fight against HIV/AIDS, tuberculosis, and malaria: current status and future perspectives. Am J Clin Pathol. 2009;131:844-8.

2. Joint United Nations Programme on HIV/AIDS (UNAIDS). Global HIV statistics. In: Fact sheet July 2017: UNAIDS; 2017. http://www.unaids.org/sites/default/ files/media_asset/UNAIDS_FactSheet_en.pdf. Accessed 22 Sept 2017.

3. Joint United Nations Programme on HIV/AIDS (UNAIDS). Ending AIDS: Progress towards the 90-90-90 targets. UNAIDS. 2017. http://www.unaids. org/sites/default/files/media_asset/Global_AIDS_update_2017_en.pdf Accessed 22 Sept 2017.

4. Sippel L, Kiziak T, Woellert F, Klingholz R. Africa's Demographic Challenges How a young population can make development possible. Berlin Institute for Population and Development. 2011. http://www.berlin-institut.org/ fileadmin/user_upload/Afrika/Africas_demographic_challenges.pdf Accessed 22 Sept 2017.

5. Singh S, Darroch J. Adding it up: costs and benefits of contraceptive services—estimates for 2012. New York: Guttmacher Inst United Nations Popul Fund; 2012.

6. Darroch JE. Trends in contraceptive use. Contraception. 2013;87:259-63.

7. Stephenson R, Vwalika B, Greenberg L, Ahmed Y, Vwalika C, Chomba E, et al. A randomized controlled trial to promote long-term contraceptive use among HIV-serodiscordant and concordant positive couples in Zambia. J Women's Health. 2011:20:567-74.

8. Wanyenze RK, Tumwesigye NM, Kindyomunda R, Beyeza-Kashesya J, Atuyambe L, Kansiime A, et al. Uptake of family planning methods and unplanned pregnancies among HIV-infected individuals: a cross-sectional survey among clients at HIV clinics in Uganda. J Int AIDS Soc. 2011;14:35.

9. Baumgartner JN, Green M, Weaver MA, Mpangile G, Kohi TW, Mujaya SN, et al. Integrating family planning services into HIV care and treatment clinics in Tanzania: evaluation of a facilitated referral model. Health Policy Plan. 2014; 29:570-9.

10. Kashagam E, Ngocho JS. Prevalence of modern dontraceptive methods use among women living with HIV attending care and treatment clinic at Amana Hospital Dar Es Salaam, Tanzania. Int J Soc Sci Humanit Invent. 2015:2:1740-6.

11. Reynolds HW, Janowitz B, Wilcher R, Cates W. Contraception to prevent HIV-positive births: current contribution and potential cost savings in PEPFAR countries. Sex Transm Infect. 2008;84(Suppl 2)

12. Sweat MD, O'Reilly KR, Schmid GP, Denison J, de Zoysa I. Cost-effectiveness of nevirapine to prevent mother-to-child HIV transmission in eight African countries. AIDS. 2004;18:1661-71.

13. Family Health International 360 (FHI). Integrating family planning into HIV programs: evidence-based practices. Durham, FHI 360; 2013. https://www. fhi360.org/resource/integrating-family-planning-hiv-programs-evidencebased-practices. Accessed 22 Sept 2017

14. Wilcher R, Cates W, Gregson S. Family planning and HIV: strange bedfellows no longer. AIDS. 2009;23(Suppl 1):S1-6.
15. Homsy J, Bunnell R, Moore D, King R, Malamba S, Nakityo R, et al. Reproductive intentions and outcomes among women on antiretroviral therapy in rural Uganda: a prospective cohort study. PLoS One. 2009;4(1):e4149.

16. Rochat TJ, Richter LM, Doll HA, Buthelezi NP, Tomkins A, Stein A. Depression among pregnant rural south African women undergoing HIV testing. JAMA. 2006:295:1376-8.

17. The Inter-agency Task Team for Prevention and Treatment of HIV Infection in Pregnant Women, Mothers, and their Children. Preventing unintended pregnancies and HIV: strategic framework 2011-2015. Geneva: WHO; 2011. http://www.who.int/reproductivehealth/publications/linkages/HIV_and_ unintended_pregnancies_SF_2011_2015.pdf Accessed 22 Sept 2017

18. Bezerra LMD. Global report : UNAIDS report on the global AIDS epidemic 2010. Urban Res. 2010:3:229-30.

19. Tanzania Commission for AIDS (TACAIDS), Zanzibar AIDS Commission (ZAC), National Bureau of Statistics (NBS), Office of the Chief Government Statistician (OCGS), and ICF International 2013. Tanzania HIV/AIDS and malaria indicator survey 2011-12. Dar es Salaam: TACAIDS, ZAC, NBS, OCGS, and ICF International; 2012. https://dhsprogram.com/pubs/pdf/AIS11/AIS11. pdf Accessed 22 Sept 2017

20. Ministry of Health and Social Welfare, National AIDS Control Programme. Tanzania National Guidelines for the management of HIV and AIDS. 5th ed. Dar es Salaam: Ministry of Health and Social Welfare, National AIDS Control Programme; 2015. https://aidsfree.usaid.gov/sites/default/files/04_11_2016. tanzania_national_guideline_for_management_hiv_and_aids_may_2015. tagged.pdf Accessed 22 Sept 2017

21. Ministry of Health, Community Development, Gender, Elderly and Children (MoHCDGEC) [Tanzania Mainland], Ministry of Health (MoH) [Zanzibar], National Bureau of Statistics (NBS), Office of the Chief Government Statistician (OCGS), and ICF. Tanzania demographic and health survey and malaria indicator survey (TDHS-MIS) 2015-16. Dar es Salaam and Rockville: MoHCDGEC, MoH, NBS, OCGS, and ICF; 2016. https://dhsprogram.com/ pubs/pdf/FR321/FR321.pdf Accessed 22 Sept 2017

22. United Nations Department of Economic and Social Affairs (UN DESA). World fertility patterns 2015: data booklet. New York: UN DESA; 2015. http:// www.un.org/en/development/desa/population/publications/pdf/fertility/ world-fertility-patterns-2015.pdf Accessed 22 Sept 2017

23. Fleischman J. HIV and family planning integration in Tanzania. Washington, DC: Center for Strategic and International Studies; 2012. https://csis-prod.s3. amazonaws.com/s3fs-public/legacy_files/files/publication/120720_ Fleischman_HIVFamPlan_Web.pdf. Accessed 22 Sept 2017

24. Family Health International (FHI). Family planning and HIV integration: approaching the tipping point. Research Triangle Park: FHI; 2010. https:// www.fhi360.org/sites/default/files/media/documents/FPHIVoverview1.pdf Accessed 22 Sept 2017

25. Popluation Action International. The benefits of integrating Hiv and family planning programs. Washington DC: Population Action International; 2012 http://pai.org/wp-content/uploads/2012/07/FPHIV_Integration_FINAL.pdf Accessed 22 Sept 2017

26. Haberlen SA, Narasimhan M, Beres LK, Kennedy CE. Integration of family planning services into HIV care and treatment services: a systematic review. Stud Fam Plan. 2017:48:153-77.

27. Duerr A, Hurst S, Kourtis AP, Rutenberg N, Jamieson DJ. Integrating family planning and prevention of mother-to-child HIV transmission in resourcelimited settings. Lancet. 2005:366:261-3.

28. Joshi B, Velhal G, Chauhan S, Kulkarni R, Begum S, Nandanwar YS, et al. Linking HIV and family planning services to improve dual methods of contraception among women infected with HIV in Mumbai, Maharashtra, India. Indian J Med Res. 2016;143:464-73.

29. Spaulding AB, Brickley DB, Kennedy C, Almers L, Packel L, Mirjahangir J, et al Linking family planning with HIV/AIDS interventions: a systematic review of the evidence. AIDS. 2009;23(Suppl 1):S79-88.

30. Grossman D, Onono M, Newmann SJ, Blat C, Bukusi EA, Shade SB, et al. Integration of family planning services into HIV care and treatment in Kenya: a cluster-randomized trial. AIDS. 2013;27(Suppl 1):S77-85.

31. Mccarraher DR, Vance G, Gwarzo U, Taylor D, Chabikuli ON. Changes in contraceptive use following integration of family planning into ART services in Cross River state, Nigeria. Stud Fam Plan. 2011;42:283-90.

32. Kosgei RJ, Lubano KM, Shen CY, Wools-Kaloustian KK, Musick BS, Siika AM, et al. Impact of integrated family planning and HIV care services on contraceptive use and pregnancy outcomes: a retrospective cohort study. J Acquir Immune Defic Syndr. 2011;58(5):e121-1126. 
33. Liambila W, Askew I, Mwangi J, Ayisi R, Kibaru J, Mullick S. Feasibility and effectiveness of integrating provider-initiated testing and counselling within family planning services in Kenya. AIDS. 2009;23(Suppl 1):S115-21.

34. Reynolds HW, Sutherland EG. A systematic approach to the planning, implementation, monitoring, and evaluation of integrated health services. BMC Health Serv Res. 2013;13:168.

35. World Health Organization (WHO). Guidance on provider-initiated HIV testing and counselling in health facilities. Geneva: WHO; 2007. http://apps.who.int/iris/ bitstream/10665/43688/1/9789241595568_eng.pdf Accessed 22 Sept 2017

36. International Planned Parenthood Federation (IPPF), United National Population Fund (UNFPA), World Health Organization (WHO), Joint United Nations Programme on HIV/AIDS (UNAIDS), Global Network for and by People Living with HIV (GNP+), International Community of Women Living with HIV/AIDS (ICW) and Young Positives. Rapid assessment tool for Sexual \& Reproductive Health and HIV linkages: a generic guide. London: IPPE, UNFPA, WHO, UNAIDS, GNP+, ICW, Young Positives; 2009. https://www. unfpa.org/sites/default/files/pub-pdf/rapidassessmenttoolsrhlinkages_2009_ en.pdf Accessed 22 Sept 2017

37. World Health Organization (WHO), United States Agency for International Development (USAID), Family Health International. Strategic considerations for strengthening the linkages between family planning and HIV/AIDS policies, programs, and services. Geneva: WHO; 2009. http://www.who.int/ reproductivehealth/publications/linkages/fp_hiv_strategic_considerations. pdf Accessed 22 Sept 2017

38. World Health Organization (WHO). Service availability and readiness assessment (SARA): an annual monitoring system for service delivery, reference manual, version 2.2. Geneva: WHO; 2015. http://apps.who.int/iris/bitstream/ 10665/149025/1/WHO_HIS_HSI_2014.5_eng.pdf?ua=1 Accessed 22 Sept 2017

39. United Republic of Tanzania (URT) and World Health Organization (WHO). Health systems profile in Tanzania: URT, WHO; 2004. http://mbaralidc.go.tz/ storage/app/media/uploaded-files/Health-tanzania.pdf. Accessed 26 Oct 2017

40. United States Agency for International Development (USAID). Family planning and HIV/AIDS integration profile in Tanzania: USAID; 2012. https://www.k4health.org/sites/default/files/FP-HIV-TANZANIA-2012-01-23. pdf Accessed 22 Sept 2017

41. United States Agency for International Development (USAID). Family Planning and HIV Integrated Supply Chains. USAID Issue Br. 2014. https://www.usaid.gov/sites/default/files/documents/1864/DELIVER-FP-HIVIntegration-Brief-508.pdf Accessed 22 Sept 2017.

42. United States Agency for International Development (USAID). Family Planning and HIV Prevention Integration. USAID Issue Br. 2012. https://www.usaid.gov/ sites/default/files/documents/1864/fp_hiv.pdf Accessed 22 Sept 2017.

43. Li J. Integration of HIV/AIDS and family planning. Lancet. 2005;366:1077.

44. Lisy K. Integration of HIV/AIDS services with maternal, neonatal and child health, nutrition, and family planning services. Public Health Nurs. 2013;30:451-3.

45. Bradley H, Bedada A, Tsui A, Brahmbhatt H, Gillespie D, Kidanu A. HIV and family planning service integration and voluntary HIV counselling and testing client composition in Ethiopia. AIDS Care. 2008;20:61-71.

46. Bradley $\mathrm{H}$, Gillespie D, Kidanu A, Bonnenfant YT, Karklins S. Providing family planning in Ethiopian voluntary HIV counseling and testing facilities: client, counselor and facility-level considerations. AIDS. 2009;23(Suppl 1):S105-14.

47. Creanga AA, Bradley HM, Kidanu A, Melkamu Y, Tsui AO. Does the delivery of integrated family planning and HIV/AIDS services influence communitybased workers' client loads in Ethiopia? Health Policy Plan. 2007;22:404-14.

48. Ndhlovu L, Searle C, Miller R, Fisher A, Snyman E, Sloan N. Reproductive health services in KwaZulu Natal, South Africa: a situation analysis study focusing on HIV/AIDS services. Horizons Researc Update. 2003. http://www. popcouncil.org/uploads/pdfs/horizons/kznsitanlru.pdf Accessed 22 Spt 2017.

49. Askew I, Maggwa NB. Integration of STI prevention and management with family planning and antenatal care in sub-Saharan Africa - what more do we need to know? Int Fam Plan Perspect. 2002;28:77-86.

50. Church K, Mayhew SH. Integration of STI and HIV prevention, care, and treatment into family planning services: a review of the literature. Stud Fam Plan. 2009;40:171-86.

51. Mayhew SH, Lush L, Cleland J, Walt G. Implementing the integration of component services for reproductive health. Stud Fam Plan. 2000;31:151-62.

52. Gichuhi W, Bradley S, Hardee K. Provision and use of family planning in the context of HIV/AIDS in Kenya: perspectives of providers, family planning and ANC clients and HIV-positive women. Policyp Project. 2004; http://www. policyproject.com/pubs/countryreports/Ken_FGD.pdf Accessed 22 Spt 2017

53. Marchal B, De Brouwere V, Kegels G. Viewpoint : HIV/AIDS and the health workforce crisis : what are the next steps? Trop Med Int Heal. 2005;10:300-4.
54. Liambilia W, Askew I, Ayisi R, Gathitu M, Mwangi J, Homan R. Feasibility, acceptability, effect and cost of integrating counseling and testing for HIV within family planning Services in Kenya. FRONTIERS final report. Wasnington DC: Population Council; 2008. http://pdf.usaid.gov/pdf_docs/ Pnadn569.pdf Accessed 22 Sept 2017

55. Zotti ME, Pringle J, Stuart G, Boyd WA, Brantley D, de Ravello L. Integrating HIV prevention in reproductive health settings. J Public Health Manag Pract. 2010;16:512-20.

56. Johnson K, Varallyay I, Ametepi P. Integration of HIV and family planning services in sub-Saharan Africa: a review of the literature, current recommendations, and evidence from the service provision assessment health faculty surveys. DHS analytical studies no. 30. Calverton: ICF International; 2012. http://paa2013.princeton.edu/papers/132217 Accessed 22 Sept 2017

57. Thomas JC, Reynolds H, Bevc C, Tsegaye A. Integration opportunities for HIV and family planning services in Addis Ababa, Ethiopia: an organizational network analysis. BMC Health Serv Res. 2014;14:22.

58. Dussault G, Dubois CA. Human resources for health policies: a critical component in health policies. Hum Resour Health. 2003;1:1 doi.org/https://doi.org/10.1186/1478-4491-1-1

59. Mutemwa R, Mayhew S, Colombini M, Busza J, Kivunaga J, Ndwiga C. Experiences of health care providers with integrated HIV and reproductive health services in Kenya: a qualitative study. BMC Health Serv Res. 2013;13:18

60. Ministry of Health and Social Welfare (MoHSW) [Tanzania Mainland], Ministry of Health (MoH) [Zanzibar], National Bureau of Statistics (NBS), Office of the Chief Government Statistician (OCGS), and ICF International 2015. Tanzania service provision assessment survey (TSPA) 2014-15. Dar es Salaam, and Rockville: MoHSW, MoH, NBS, OCGS, ICF International; 2015. https://dhsprogram.com/pubs/pdf/SPA22/SPA22.pdf Accessed 22 Sept 2017

61. Beyene W, Jira C, Sudhakar M. Assessment of quality of health care in jimma zone, southwest ethiopia. Ethiop J Health Sci. 2011;21(Suppl 1):49-58.

62. National Bureau of Statistics (NBS) [Tanzania] and Macro International Inc. 2007. Tanzania service provision assessment survey 2006. Dar es Salaam: National Bureau of Statistics and Macro International Inc; 2007. https://dhsprogram.com/pubs/pdf/SPA12/SPA12.pdf Accessed 22 Sept 2017

63. Criniti SM, Aaron E, Hilley A, Wolf S. Integration of routine rapid HIV screening in an urban family planning clinic. J Midwifery Women's Heal. 2011;56:395-9.

64. Kida T. Provision and access of health Care Services in the Urban Health Care Market in Tanzania. ESRF discussion paper no. 42. Dar es Salaam: The Economic and Social Research Foundation; 2012. http://esrf.or.tz/docs/ PROVISIONANDACCESSOFHEALTHCARESERVICESINTHEURBANHEALTH CAREMARKETINTANZANIA.pdf Accessed 22 Sept 2017

65. COWI, Goss Gilroy Inc, EPOS Health Consultants. Joint external evaluation of the health sector in Tanzania, 1999-2006. Koege: Ministry of Foreign Affairs of Denmark; 2007. http://www.oecd.org/countries/tanzania/39837890.pdf Accessed 22 Sept 2017

66. Chengsorn N, Bloss E, Anekvorapong R, Anuwatnonthakate A, Wattanaamornkiat W, Komsakorn S, et al. Tuberculosis services and treatment outcomes in private and public health care facilities in Thailand, 2004-2006. Int J Tuberc Lung Dis. 2009;13:888-94.

67. Ogwal-Okeng JW, Obua C, Waako P, Aupont O, Ross-Degnan D. A comparison of prescribing practices between public and private sector physicians in Uganda. East Afr Med J. 2004;Suppl:S12-6.

68. Basu S, Andrews J, Kishore S, Panjabi R, Stuckler D. Comparative performance of private and public healthcare systems in low- and middleincome countries: a systematic review. PLoS Med. 2012;9:19.

69. Rannan-Eliya RP, Wijemanne N, Liyanage IK, Dalpatadu S, de Alwis S, Amarasinghe $\mathrm{S}$, et al. Quality of inpatient care in public and private hospitals in Sri Lanka. Health Policy Plan. 2015;30(suppl 1):146-58.

70. The United Nations Children's Fund (UNICEF). Tanzania health budget brief. Briefing. FY 2011/12-FY 2015/16. Dar es Salaam: UNICEF; 2015. https://www.unicef.org/tanzania/UNICEF-TZ-BB-Health-WEB-final.pdf Accessed 22 Sept 2017

71. World Bank. Tanzania economic update: the road less travelled. Dar es Salaam: World Bank; 2016. http://documents.worldbank.org/curated/en/ 302151467992051044/pdf/105764-NWP-ADD-SERIES-PUBLIC-MAY-19-11AMDC-TIME-8th-Tanzania-Economic-Update-Report-FINAL.pdf Accessed 22 Sept 2017

72. Irfan SM, ljaz A. Comparison of service quality between private and public hospitals: empirical evidences from Pakistan. J Qual Technol Manag. 2011; $\operatorname{VII}(I): 1-22$. 
73. Al Khattab S, Aborumman AH. Healthcare service quality: comparing public and private hospitals in Jordan. Int Bus Manag. 2011;5:247-54.

74. Yousapronpaiboon K. A comparison of service quality between private and public hospitals in Thailand. Int J Bus Soc Sci. 2013:4:176-84.

75. Steinmann L, Zweifel P. On the (in)effeciency of Swiss hospitals. Appl Econ. 2003:35:361-70

76. Mayhew SH. Integration of STI services into FP/MCH services: health service and social contexts in rural Ghana. Reprod Health Matters. 2000;8:112-24.

77. Owens DK. Improving practice guidelines with patient-specific recommendations. Ann Int Med. 2011;154:638-9.

78. De Jongh T, Gurol-Urganci I, Allen E, Zhu NJ, Atun R. Barriers and enablers to integrating maternal and child health services to antenatal care in low and middle income countries. BJOG. 2016;123:549-57.

79. Chege JN, Askew I, Mosery N, Ndube-Nxumalo M, Kunene B, Beksinska M, et al. Feasibility of introducing a comprehensive integrated package of antenatal care services in rural public clinics in South Africa. FRONTIERS Fnal Report. 2005. http://pdf.dec.org/pdf_docs/PNADD878.pdf Accessed 22 Sept 2017.

80. Geelhoed D, Lafort Y, Chissale É, Candrinho B, Degomme O. Integrated maternal and child health services in Mozambique: structural health system limitations overshadow its effect on follow-up of HIV-exposed infants. BMC Health Serv Res. 2013;13:207.

81. Jereni BH, Muula AS. Availability of supplies and motivations for accessing voluntary HIV counseling and testing services in Blantyre, Malawi. BMC Health Serv Res. 2008;8:17.

82. Lesotho Ministry of Health. 2014. Lesotho PHC Revitalization- Services Availability and Readiness Assessment- Integrated Supervision Report MoHSW Assessment Team. https://www.hfgproject.org/lesotho-phcrevitalization-services-availability-readiness-assessment-integratedsupervision-report/ Accessed 22 Sept 2017.

\section{Submit your next manuscript to BioMed Central and we will help you at every step:}

- We accept pre-submission inquiries

- Our selector tool helps you to find the most relevant journal

- We provide round the clock customer support

- Convenient online submission

- Thorough peer review

- Inclusion in PubMed and all major indexing services

- Maximum visibility for your research

Submit your manuscript at www.biomedcentral.com/submit 